\title{
Manifiesto por las Ciencias Sociales CLACSO 50 años
}

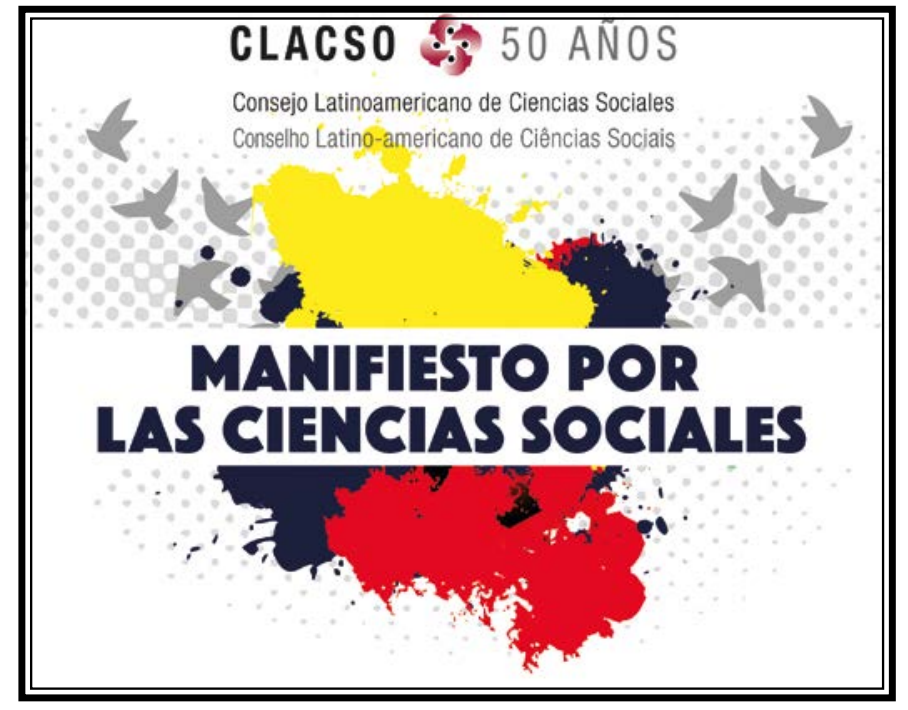

Elaborado por las y los participantes del I Foro "Las Ciencias Sociales en Colombia, América Latina y el Caribe. Memorias, desplazamientos epistemológicos, emergencias y re-existencias", realizado en Bogotá, Colombia, entre el 30 de octubre y el 1 de noviembre de 2017 en el marco de los 50 Años de CLACSO.

Después de sentir el nada mentido sortilegio de las calles de Bogotá, de haber hallado, en medio del agitado temperamento de la ciudad, un espacio para el acontecer del pensamiento, un destello arrebatado al tiempo para ser en la reflexión, de hallar una posibilidad para la conversación, un instante para darse en las palabras, para reconocerse en la vigencia de antiguas preguntas y posicionarse ante la emergencia de nuevas inquietudes, nació entre nosotros el deseo de escribir un Manifiesto más por las Ciencias Sociales en el que fuera posible dar cuenta de la polifonía que tuvo lugar los dos últimos días de octubre.

\section{Pero no fue un octubre cualquiera...}

A cien años de la Revolución Bolchevique, este octubre conmemorativo nos obligaría a pensar de nuevo el paisaje de las luchas sociales en el mundo contemporáneo. Cien años después de los diez días que estremecieron al mundo, cien años después de las voces que declaraban el Socialismo como real, el tono de nuestras preguntas es otro. Un siglo después del octubre rojo la partitura de la lucha obrera tendrá que ser reinventado, y no fueron pocas las voces que en este encuentro en torno a las Ciencias Sociales dieron cuenta de ello.

\section{Pero no fue sólo un octubre rojo...}

En el paisaje de lo más próximo, de lo que nos inquieta en nuestras geografías, ante aquello que reclama un pensar situado, este octubre fue también trágico y no sólo conmemorativo. Una nueva masacre cometida por las fuerzas estatales contra campesinos de Tumaco y el asesinato de varios dirigentes sociales, sindicales y agrarios que luchan por la implementación del Acuerdo de la Habana, desataron nuevamente la marea teñida de sangre. En tiempos de transición hacia la Paz, el Terrorismo de Estado en Colombia persiste.

\section{Pero no sólo fue sólo un octubre trágico...}

Mientrasconversábamos, mientraslas palabras fueron agenciando nuevas reflexiones, mientras discutíamos sobre la necesidad dialéctica entre teoría y praxis, se declaró y se convocó la Minga por la Vida. Los pueblos originarios del sur del país, esa geografía tatuada con el signo de la resistencia y en cuyas historias parece imposible 
cualquier resignación, decidieron exigir al Estado que se cumpla lo acordado y lo hicieron regresando al único lugar en el que siempre seremos escuchados: La calle. El escenario se repite, y en nuestras aulas de seguro el eco de estas voces ancestrales también será escuchado. Y no sólo las voces de la Minga, también serán escuchadas las voces que luchan contra el Feminicidio y el Juvenicidio en la América Latina; también serán escuchadas las voces que vuelven a luchar contra la desaparición forzada y que hoy esperan saber la verdad sobre la muerte de Santiago Maldonado en Argentina y las voces que continúan exigiendo aparición con vida en Ayotzinapa. Los alzamientos campesinos que hoy resisten en el Bajo Aguán hondureño tocarán allí donde el pensamiento se torna emancipación, y los ecos de un pueblo que mantiene viva la Revolución Bolivariana en Venezuela hallarán en nuestras pedagogías otro lugar para seguir luchando.

Nuestro Manifiesto por las Ciencias Sociales es también un Manifiesto por los Movimientos Sociales, pues en ellos, en las calles que se recrean en nuestras aulas, también hallamos el nada mentido sortilegio de nuestra Re-Existencia.

Alejados de cualquier pretensión de dar cuenta de la totalidad de lo dicho en estos días, este Manifiesto es un gesto colectivo que pretende ser memoria compartida, trama hecha de palabras y consignas, de preguntas y enunciados cuya fuerza expresiva resonó en cada uno de los espacios donde se hizo posible la escucha.

\section{Pero no sólo de palabras está hecho este Manifiesto...}

También son los silencios, esos resquicios donde se aloja lo innombrable y lo indecible, los que nos obligan a suspender el hablar precipitado y disponer la escucha reflexiva. En este Manifiesto también hablan las miradas, los gestos de los cuerpos, los rostros expectantes y los susurros de la sospecha. Un Manifiesto por las Ciencias Sociales será siempre un texto inacabado y no estará hecho sólo de palabras. Así reconocemos las preguntas que quedaron abiertas, las inquietudes no resueltas, el pletórico escenario de la multiplicidad que nos fue arrojando a otros modos de pensar. También nos reconocemos en esa zona donde nada queda dicho de una vez y para siempre.

Incluso un Manifiesto por las Ciencias Sociales tendría que ser expresión de lo que desborda el conjunto de prácticas discursivas que históricamente nos han convocado; porque sentimos que las fronteras disciplinares son cada vez más difusas, y otros lugares de enunciación vienen a interpelarnos.

¿Desde dónde hablamos? No sólo desde las Ciencias Sociales, y éste es ya un desplazamiento que nos hace comunes. Los lenguajes, antes exiliados o proscritos, resonaron sin temor en nuestras comprensiones. El arte, la literatura, la Filosofía, los saberes ancestrales, los saberes populares, y sobre todo la experiencia, configuran hoy un mapa posible para pensar las Ciencias Sociales.

Y después de dos telúricos días dispuestos a la reflexión en torno a los desplazamientos epistemológicos y metodológicos, las epistemes sociales y la paz territorial, los estudios de memoria y la crisis de los sistemas de evaluación y medición de nuestros saberes, manifestamos:

1. El desplazamiento hacia otros campos de saber que emergen de las tensiones propias de las nuevas espiritualidades del tiempo presente y que exigen a las Ciencias Sociales una apertura epistémica, y a la virtud crítica una práctica transformadora.

2. Manifestamos... Los significativos $y$ decisivos aportes que los Estudios Feministas han hecho al conjunto de las Ciencias Sociales, activando otras prácticas intelectuales contrahegemónicas y desplazando la mirada hacia relaciones de poder antes invisibilizadas por la Episteme dominante.

3. Manifestamos... El reposicionamiento de la dimensión práctica de los Derechos Humanos más allá de su dimensión cognitiva y la necesidad de articular su ejercicio en los escenarios que configuran lo educativo. 
4. Manifestamos... La necesidad de superar visiones reduccionistas en torno a las Políticas Públicas, reconociendo otros lugares para agenciar su comprensión y situando otros para activar su potencial transformador.

5. Manifestamos... El deseo de develar el compromiso ético, la praxis política y la militancia investigativa cuando de trabajar con y desde las comunidades se trata.

6. Manifestamos... La necesidad de hallar posibilidades metodológicas que superen los rezagos del positivismo y permitan construir desde los territorios, otros caminos del saber.

7. Manifestamos... La necesidad de reconocer las contradicciones, las texturas, las tensiones que se despliegan en las comunidades y la multiplicidad de matices de las expresiones de la Re-Existencia.

8. Demandamos el compromiso y diligencia del Estado en el aseguramiento efectivo de la soberanía política, cultural y alimentaria en las diversas regiones del país, hoy afectadas por los efectos devastadores del extractivismo minero y agrícola. Reivindicamos el derecho soberano de las comunidades campesinas e indígenas a proteger su territorio de estas prácticas y a un sí rotundo por la vida y por sus formas culturales de vínculo orgánico y cuidado del territorio.

9. Respaldamos las demandas que hoy se hacen a las autoridades nacionales por parte de las víctimas del conflicto armado y desde los más diversos sectores del país, por una implementación seria, ágil y transparente de todo lo pactado con las FARC-EP en el acuerdo de La Habana. Rechazamos, por exponer al país a formas diversas de violencia y por constituir formas perversas de acumulación de capital electoral, las demoras que en el Congreso de la República se han causado en la aprobación de lo consignado en el Acuerdo de La Habana.

10. Urgimos a las autoridades judiciales y de policía, nacionales y departamentales, a diseñar e implementar en forma inmediata todas las medidas necesarias para proteger a los líderes sociales en los diversos territorios indígenas y campesinos del país. Estas medidas incluyen seguridad integral, investigación profunda de los mecanismos y responsables de tales crímenes, y empoderamiento de las comunidades en la apropiación y reforzamiento de prácticas protectoras y en la gestión de los riesgos de seguridad presentes en la actividad de sus líderes.

11. Reclamamos la destinación prioritaria de recursos públicos suficientes a la provisión de bienes sociales básicos y seguridad a las comunidades campesinas del Sur del país y otras regiones que se ven estructuralmente forzadas a continuar cultivando coca en sus territorios. Reivindicamos los derechos fundamentales de los que estos compatriotas son titulares y exigimos se avance con prioridad y prontitud en la construcción de la institucionalidad local necesaria para asegurar tales derechos.

12. Reiteramos, como científicos y educadores, la necesidad de transformar profundamente el sistema educativo para que este sirva a la construcción permanente de la paz. A la apropiación de recursos suficientes para fortalecer la infraestructura y condiciones laborales de los maestros, especialmente en las zonas del país más afectadas por la guerra, debe seguir inmediatamente la reestructuración de las prácticas educativas y de la vida escolar a partir de una reflexión ético-política profunda, incluyente e intercultural que permita cultivar los vínculos, la celebración, la expresión y los sentidos múltiples, creativos y constructivos, de la vida, la convivencia y la realización humana.

13. Enfatizamos que las Ciencias Sociales en la Colombia de hoy, son imprescindibles para construir una cultura del reconocimiento de esas realidades y evitar la inadvertencia de las ignominias sufridas en todas sus expresiones, y cómo pueden ser traducidas sus dramáticas y complejas lecciones en propuestas de formación social. En este sentido, su responsabilidad es de manera conjunta e integrada entre todas sus disciplinas, contribuir en la generación y divulgación de conocimiento que favorezca conocer y comprender en detalle lo que ha venido 
sucediendo sistemáticamente y hacer de ese conocimiento la fuente de un compromiso con la sociedad para deliberar de forma constante sobre ese devenir histórico como punto de partida de decisiones que propendan por un cambio en prácticas, lenguajes y relaciones que inspiren una sociedad que valore y respete la vida independiente de sus diferencias culturales e ideológicas.

14. Reclamamos la necesidad de reescribir la historia, hasta ahora narrada en gran parte por quienes han coadyuvado a esa gran tragedia nacional, por una historia en la que las víctimas de tanto abandono, odio e incomprensión nos ofrezcan una nueva gramática que redirija los valores hacia una nueva forma de convivencia y un nuevo ordenamiento social en la que todos tengan lugar.

15. Consideramos que en ese camino, es indispensable persistir y contribuir en la apertura de una cultura democrática. Las Ciencias Sociales están llamadas a sortear con las pretensiones de quienes quieren ponerlas al servicio de intereses de ciertos sectores sociales en detrimento de las mayorías. Su aporte en la compresión de las diferentes manifestaciones sociales, en una sociedad que como la Colombiana ha pretendido calificarse como democrática, es de trascendencia sustancial en la perspectiva de contener la estigmatización y la revictimización de muchas de sus gentes y comunidades.

16. Manifestamos que las Ciencias Sociales deben avanzar hacia superar todo antropocentrismo. Esa lógica de lo humano como dominador de la naturaleza, o de la función de la naturaleza al servicio de lo humano, ha sido la más notoria de todas las violencias, al punto de llevar al planeta a una extrema fragilidad. Es hora de una horizontalidad en esa relación y por ello, una proclama que reconduzca el capitalismo salvaje, depredador y extractivista hacia una economía para la vida, el respeto a su diversidad y la soberania.

17. Afirmamos la necesidad de reconocer la importancia de seguirnos consolidando como una comunidad académica con un rol activo en la producción científica, asumido desde una posición reflexiva, crítica y autocrítica que nos proteja de los dogmatismos y de nuestros propios prejuicios; sólo así podremos abrirnos a la construcción de un trabajo académico colaborativo e interdisciplinario.

18. Reafirmamos nuestras búsquedas para superar la sobre valoración del método a favor de la búsqueda del equilibrio, nunca completo, entre la fundamentación teórica, el método y el trabajo de campo. En todo caso es necesario respetar las diferencias teóricas, prácticas y metodológicas de las disciplinas y los saberes.

19. Consideramos que la circulación, transmisión, difusión y democratización del conocimiento es fundamental para la transformación de las sociedades. Por ello vemos con preocupación la manera en que se viene desplazando la responsabilidad y el sentido mismo de la medición y reconocimiento de los mecanismos de divulgación por parte de las comunidades académicas del país, para ser entregado de manera acrítica a las lógicas y parámetros de sistemas de indexación definidos por Colciencias, que tienen una intencionalidad de controlar y delimitar lo que se divulga, es decir, en contravía de la democratización antes enunciada, así como se hace necesario develar otros mecanismos corporativos que subyacen en los diferentes sistemas de medición en Latinoamérica y el Caribe.

Bogotá D.C., Colombia. 1 de noviembre de 2017 